\title{
A new type of flexible $\mathrm{CP} 12$ protein in the marine diatom Thalassiosira pseudonana
}

\author{
Hui Shao', Wenmin Huang 1,2, Luisana Avilan ${ }^{1,3}$, Véronique Receveur-Bréchot ${ }^{1}$, Carine Puppo ${ }^{1}$, Rémy Puppo ${ }^{4}$,
} Régine Lebrun ${ }^{4}$, Brigitte Gontero ${ }^{1 *}$ (D) and Hélène Launay ${ }^{1 *}$

\begin{abstract}
Background: CP12 is a small chloroplast protein that is widespread in various photosynthetic organisms and is an actor of the redox signaling pathway involved in the regulation of the Calvin Benson Bassham (CBB) cycle. The gene encoding this protein is conserved in many diatoms, but the protein has been overlooked in these organisms, despite their ecological importance and their complex and still enigmatic evolutionary background.
\end{abstract}

Methods: A combination of biochemical, bioinformatics and biophysical methods including electrospray ionizationmass spectrometry, circular dichroism, nuclear magnetic resonance spectroscopy and small X ray scattering, was used to characterize a diatom CP12.

Results: Here, we demonstrate that CP12 is expressed in the marine diatom Thalassiosira pseudonana constitutively in dark-treated and in continuous light-treated cells as well as in all growth phases. This CP12 similarly to its homologues in other species has some features of intrinsically disorder protein family: it behaves abnormally under gel electrophoresis and size exclusion chromatography, has a high net charge and a bias amino acid composition. By contrast, unlike other known CP12 proteins that are monomers, this protein is a dimer as suggested by native electrospray ionization-mass spectrometry and small angle X-ray scattering. In addition, small angle X-ray scattering revealed that this CP12 is an elongated cylinder with kinks. Circular dichroism spectra indicated that CP12 has a high content of a-helices, and nuclear magnetic resonance spectroscopy suggested that these helices are unstable and dynamic within a millisecond timescale. Together with in silico predictions, these results suggest that T. pseudonana CP12 has both coiled coil and disordered regions.

Conclusions: These findings bring new insights into the large family of dynamic proteins containing disordered regions, thus increasing the diversity of known CP12 proteins. As it is a protein that is more abundant in many stresses, it is not devoted to one metabolism and in particular, it is not specific to carbon metabolism. This raises questions about the role of this protein in addition to the well-established regulation of the CBB cycle.

Keywords: Coiled coil, Diatom, Intrinsically disordered protein IDP, Nuclear magnetic resonance, Photosynthesis, Small angle $X$-ray scattering

*Correspondence: bmeunier@imm.cnrs.fr; helene.launay@univ-amu.fr ${ }^{1}$ CNRS, BIP UMR 7281, Aix Marseille Univ, 31 Chemin Joseph Aiguier, 13402 Marseille Cedex 20, France

Full list of author information is available at the end of the article

\section{Introduction}

Chloroplast protein of $12 \mathrm{kDa}(\mathrm{CP} 12)$ is a small nuclear encoded protein of about 80 amino acid residues, originally described by Pohlmeyer et al. [1] that occurs in many photosynthetic organisms [2,3] and in Plantae and cyanobacteria is associated to the redox signaling pathway involved in the switch on/off of the light and dark metabolisms [4]. In higher plants, green and red algae, original author(s) and the source, provide a link to the Creative Commons licence, and indicate if changes were made. The images or other third party material in this article are included in the article's Creative Commons licence, unless indicated otherwise in a credit line to the material. If material is not included in the article's Creative Commons licence and your intended use is not permitted by statutory regulation or exceeds the permitted use, you will need to obtain permission directly from the copyright holder. To view a copy of this licence, visit http://creativecommons.org/licenses/by/4.0/. The Creative Commons Public Domain Dedication waiver (http://creativeco mmons.org/publicdomain/zero/1.0/) applies to the data made available in this article, unless otherwise stated in a credit line to the data. 
and cyanobacteria, it is associated with two enzymes, phosphoribulokinase (PRK) and glyceraldehyde 3-phosphate dehydrogenase (GAPDH) from the Calvin Benson Bassham (CBB) cycle that is responsible for $\mathrm{CO}_{2}$ assimilation [5]. This ternary complex has been well-studied and its structure has been recently solved using cryo-electron microscopy in the cyanobacterium Synechococcus elongatus [6] and using X-ray diffraction in the model higher plant Arabidopsis thaliana [7]. CP12 proteins from different organisms have some highly conserved regions such as a AWD_VEEL motif [2] and in most cases have a pair of cysteine residues at the C-terminus and/or a second pair at the $\mathrm{N}$-terminus. Although cysteine residues are order-promoting amino-acids, and likely to structure the molecule, CP12 shares some physico-chemical properties with intrinsically disordered proteins (IDPs). In agreement with predictors of intrinsic disorder, CP12 from the green alga Chlamydomonas reinhardtii [8] and later from the angiosperm $A$. thaliana [9] were shown by circular dichroism (CD) and Nuclear Magnetic Resonance (NMR) to contain little regular secondary structure in solution [10-12].

These proteins have been extensively studied in these organisms and in C. reinhardtii it is a jack-of-all-trades that cannot only bind to PRK and GAPDH under its oxidized state, thereby downregulating their activity upon complex formation in the dark, but can also perform other functions [13]. For example, it can bind metal ions $[14,15]$, and can act as a specific chaperone-like for GAPDH [16]. In the tropical legume, Stylosanthes guianensis, higher expression of CP12 increases growth, plant height and photosynthesis rate [17]. Conversely, in the tobacco Nicotiana tabacum and in the mouse-ear cress A. thaliana, antisense suppression of CP12 reduces the rate of photosynthesis and increases the expression of proteins related to oxidative stress $[18,19]$. Finally, in $A$. thaliana, one CP12 isoform is mainly expressed in nonphotosynthetic tissues (roots and floral tissues) [20]. All these studies suggest that $\mathrm{CP} 12$ proteins have other functions beyond the dark downregulation of $\mathrm{CBB}$ enzymes and could act as possible signaling proteins coordinating multiple cell actions in response to environmental variables [21].

Little is known about CP12 in the diatoms, an ecologically important group of microalgae. Diatoms have a more complex evolutionary background than the other organisms mentioned above in which $\mathrm{CP} 12$ has been studied, and the regulation of their CBB enzymes is not fully understood [22]. The complex PRK-GAPDH-CP12 does not seem to be present [23-26] though there are some studies indicating a possible presence of CP12 in these organisms [23, 27]. For example, a CP12-like protein from Thalassiosira pseudonana has been shown to be expressed under stress conditions such as low $\mathrm{CO}_{2}$ [28] or low nutrients (nitrogen, phosphorus, silicon) [29]. Even though we do not know yet the function of CP12 from T. pseudonana, because it has homology with wellstudied CP12s that allow organisms to respond to rapid changes, it is likely that this protein will have a similar role in diatoms that face fluctuating environments. The aim of this manuscript was therefore to characterize the structural properties of this protein from the marine diatom T. pseudonana, using both in silico and a range of biophysical experimental approaches.

\section{Material and methods}

\section{Diurnal expression of $T$. pseudonana CP12 in vivo}

Cells from T. pseudonana (strain CCMP 1335 from https://ncma.bigelow.org/) were grown in $\mathrm{F} / 2+\mathrm{Si}$ medium (http://www.ccap.ac.uk/) under continuous light $\left(50 \mu \mathrm{mol}\right.$ photon $\left.\mathrm{m}^{-2} \mathrm{~s}^{-1}\right)$ in an incubator (Innova 4230, New Brunswick Scientific) at $19{ }^{\circ} \mathrm{C}$ and shaken at $100 \mathrm{rpm}$. Growth of T. pseudonana was monitored using the absorbance at $680 \mathrm{~nm}$. When the cells reached the exponential phase, half of the culture was put in the dark, and half left in the light. After $24 \mathrm{~h}$, cells were collected by centrifugation for $15 \mathrm{~min}$ at $3275 \mathrm{~g}, 19^{\circ} \mathrm{C}$ with a Beckman Allegra X15R centrifuge, and resuspended in $15 \mathrm{mM}$ tris(hydroxymethyl)aminomethane (Tris), $4 \mathrm{mM}$ ethylenediaminetetraacetic acid (EDTA), $\mathrm{pH} 7.9$ with $0.5 \mu \mathrm{g} \mathrm{mL}^{-1}$ protease inhibitors (Sigma). The cells were sonicated (Sonic Ruptor 250, on ice, 4 cycles, $1 \mathrm{~min}$ sonication and $1 \mathrm{~min}$ rest), then centrifuged at $16,000 \mathrm{~g}$ for $20 \mathrm{~min}$ at $4{ }^{\circ} \mathrm{C}$ and the supernatant collected. Protein amount was measured by the Bradford protein assay using bovine serum albumin as a standard (Bio-Rad). Proteins were loaded to $12 \%$ sodium dodecyl sulfate polyacrylamide gel electrophoresis (SDS-PAGE) that was stained with Coomassie Blue or immediately transferred onto a $0.45 \mu \mathrm{m}$ nitrocellulose membrane (Thermo Fisher Scientific). The antibodies raised against recombinant His-tagged CP12 in rabbits were produced by Eurogentec (https://www.eurogentec.com/en/custom-antibodies). The membrane was incubated first with $\alpha-T$. pseudonana CP12 antibodies diluted 1: 10,000, then with goat anti-rabbit IgG horseradish peroxidase (HRP, Invitrogen) diluted 1: 10,000. Finally, the membrane was revealed with luminol-based substrate (Amersham Enhanced Chemiluminescence western blotting kit detection reagent) using ImageQuant LAS 4000 biomolecular imager (GE Healthcare).

\section{Expression of $\mathrm{CP} 12$ during different phases of growth}

A preculture of $T$. pseudonana cells in $\mathrm{F} / 2+\mathrm{Si}$ medium, under continuous light $\left(50 \mu \mathrm{mol}\right.$ photon $\left.\mathrm{m}^{-2} \mathrm{~s}^{-1}\right)$, was first grown at $19{ }^{\circ} \mathrm{C}$, shaken at $100 \mathrm{rpm}$ under high 
$\mathrm{CO}_{2}$ concentration $(20,000 \mathrm{ppm})$ to increase biomass. After five days, the pellet of a $40 \mathrm{~mL}$ aliquot of this preculture obtained by centrifugation at $3275 \mathrm{~g}$ for $15 \mathrm{~min}$ at $4{ }^{\circ} \mathrm{C}$ was washed and re-suspended in fresh $\mathrm{F} / 2+\mathrm{Si}$ medium. This was performed three times. These cells were then inoculated into fresh $\mathrm{F} / 2+\mathrm{Si}$ medium at an initial absorbance at $680 \mathrm{~nm}$ of 0.2 (pathway length $1 \mathrm{~cm}$ ) and grown under air-concentration of $\mathrm{CO}_{2}(400 \mathrm{ppm})$. Growth of $T$. pseudonana was monitored using the absorbance at $680 \mathrm{~nm}$. Every day, a volume of the culture was collected that was normalized to obtain $30 \mu \mathrm{g}$ of total proteins in cell extract. A pellet of cells was obtained after centrifugation for one minute at $3275 \mathrm{~g}$ and re-suspended into SDS-PAGE loading buffer containing $15 \mathrm{mM}$ dithiothreitol. Cell lysis and protein denaturation were performed at $95{ }^{\circ} \mathrm{C}$ for $10 \mathrm{~min}$. During the exponential phase and the beginning of the stationary phase, the expression of CP12 was monitored using western-blot analysis.

\section{In silico bioinformatic analysis}

The subcellular localization of CP12 from five species of diatoms was predicted using a signal peptide predictor dedicated to diatoms, HECTAR (https://webtools. sb-roscoff.fr/) [30]. The signal peptides of CP12 from other organisms were predicted using ChloroP (http:// www.cbs.dtu.dk/services/ChloroP/, [31]), SignalP (http:// www.cbs.dtu.dk/services/SignalP/ [32]) and TargetP (http://www.cbs.dtu.dk/services/TargetP/ [33]). These enabled the $\mathrm{N}$-terminus of the mature chloroplast $\mathrm{CP} 12$ proteins to be determined. Disordered regions were predicted using PONDR VL-XT (http://www.pondr. com/) [34], DisEMBL Remark-465 (http://dis.embl. de/) [35], IUPred2A (https://iupred2a.elte.hu/) [36] and s2D (http://www-mvsoftware.ch.cam.ac.uk/index.php/ s2D) [37]. Coiled coil regions were predicted using Paircoil (http://cb.csail.mit.edu/cb/paircoil2/paircoil2-like. html), with a minimum search window of 21 residues [38]. Amino acid frequency in the algal and diatom CP12 was analyzed by composition profiler (http://www.cprof iler.org/cgi-bin/profiler.cgi) [39] against the Protein Data Bank (PDB) (https://www.rcsb.org/).

\section{Overexpression and purification of CP12 from $T$. pseudonana}

Primers containing the NdeI and BamHI restriction sites were used to amplify and clone the CP12 gene in frame with the $\mathrm{N}$-terminal histidine tag of the pET28a expression vector (Novagen) (forward primer $5^{\prime}$ CATATGGCT GCCATTGAAGCTGCTCT $3^{\prime}$ and reverse primer $5^{\prime}$ GGATCCCTAACGGGAACCAAGGGCC $3^{\prime}$ ). This plasmid was used to transform Escherichia coli BL21(DE3) pLysS. Freshly transformed bacteria were grown in $2 \mathrm{YT}$ medium with $50 \mu \mathrm{g} / \mathrm{mL}$ kanamycin and $34 \mu \mathrm{g} / \mathrm{mL}$ chloramphenicol at $37^{\circ} \mathrm{C}$ until the absorbance at $600 \mathrm{~nm}$ reached $0.5-0.6$ ( $1 \mathrm{~cm}$ pathlength). Cultures were cooled on ice for $30 \mathrm{~min}$ and then CP12 expression was induced with $1 \mathrm{mM}$ isopropyl- $\beta$-D-1-thiogalactopyranoside (IPTG). Cells were cultured at $30^{\circ} \mathrm{C}$ overnight in an incubator (Edmund Bühler $\mathrm{GmbH}$, Fisher Bioblock Scientific), then centrifuged at $3275 \mathrm{~g}$ at $4{ }^{\circ} \mathrm{C}$ (Beckman Allegra $\mathrm{X} 15 \mathrm{R}$ centrifuge). The pellets containing cells were resuspended in $50 \mathrm{mM} \mathrm{NaH} \mathrm{PO}_{4} / \mathrm{Na}_{2} \mathrm{HPO}_{4}, 300 \mathrm{mM}$ $\mathrm{NaCl}, 10 \mathrm{mM}$ imidazole, pH 8.0 (Ni-NTA buffer). Cells were then broken by sonication (Sonic Ruptor 250, 1 min sonication and $1 \mathrm{~min}$ on ice, 4 cycles) and centrifuged at $27,000 \mathrm{~g}$ for $20 \mathrm{~min}$ at $4{ }^{\circ} \mathrm{C}$. The supernatant contained the recombinant histidine tagged $\mathrm{CP} 12$ (His-CP12) that was then purified by nickel ion affinity chromatography on Ni-NTA agarose column (Qiagen) $(1.2 \times 8 \mathrm{~cm}$ of resin). The column was equilibrated with Ni-NTA buffer. Contaminants were firstly washed out with $10 \mathrm{mM}$ imidazole until the absorbance at $280 \mathrm{~nm}$ reached a minimum, then fractions were gradually eluted with an imidazole gradient (10-250 mM imidazole, $2 \times 45 \mathrm{~mL}$ ). Proteins elution was followed by absorbance at $280 \mathrm{~nm}$. His-tagged CP12 was eluted with $150 \mathrm{mM}$ imidazole, and dialyzed with $10 \mathrm{mM}$ sodium phosphate buffer, $\mathrm{pH} 7.4$ then stored at $-20{ }^{\circ} \mathrm{C}$. Size exclusion chromatography (SEC), electrospray ionization coupled to mass spectrometry (ESI-MS) and circular dichroism (CD) were performed on CP12 after His tag removal with thrombin (T4648, Sigma) (1 U for $100 \mu \mathrm{g}$ of CP12) at room temperature for $18 \mathrm{~h}$. The sample was concentrated using a $500 \mu \mathrm{L}$ spin X-UF ultra centrifugal concentrator, Corning, $5 \mathrm{kDa}$ cut-off. After His-tag removal, CP12 was stored at $-20^{\circ} \mathrm{C}$.

\section{Determination of redox state}

The free thiol groups in CP12 were quantified using 5,5'-dithiobis-(2-nitrobenzoic acid) (DTNB) (SigmaAldrich). $2 \mu \mathrm{M}$ CP12 was mixed with $50 \mu \mathrm{M}$ DTNB in $10 \mathrm{mM}$ phosphate, $2 \mathrm{mM}$ EDTA at $\mathrm{pH} 8$ and the absorbance followed at $412 \mathrm{~nm}$. A control without the protein was recorded in parallel. Number of free $\mathrm{SH}$ groups was calculated from $\mathrm{N}=\triangle O D / \epsilon C L$ (N: number of thiol; $\epsilon$ : DTNB extinction coefficient, $14,150 \mathrm{M}^{-1} \mathrm{~cm}^{-1}$; $C$ : protein concentration in $\mathrm{M}$; $L$ : light pathlength in $\mathrm{cm}$ ).

Native electrospray ionization-mass spectrometry (ESI-MS) Prior to native ESI-MS analysis, CP12 without the histidine tag was dialyzed against $200 \mathrm{mM}$ ammonium acetate buffer (pH 8.0) using $5 \mathrm{kDa}$ cut-off concentrator columns (Spin-X, Corning). Experiments at $5 \mu \mathrm{M}$ of $\mathrm{CP} 12$ were carried out on an electrospray Q-ToF mass spectrometer (Synapt G1 HDMS, Waters) using NanoLockSpray ionisation source with borosilicate emitter (NanoES spray capillaries, Thermo Scientific). Optimized instrument 
parameters were as follows: source pressure $5.3 \mathrm{mbar}$, source temperature $20^{\circ} \mathrm{C}$, capillary voltage $1.8 \mathrm{kV}$, sampling cone voltage $180 \mathrm{~V}$, extractor cone voltage $4 \mathrm{~V}$, trap collision energy $30 \mathrm{~V}$ and transfer collision energy $20 \mathrm{~V}$. Mass spectrometer was calibrated in positive mode from 1000 to $5000 \mathrm{~m} / \mathrm{z}$ with CsI $(1 \mathrm{mg} / \mathrm{mL})$ just prior acquisition.

\section{Size exclusion chromatography}

$500 \mu \mathrm{L}$ of CP12 after histidine tag removal, at $0.5 \mathrm{mM}$ were loaded on a Hiload Superdex 200 (prep grade $26 \mathrm{~mm} \times 600 \mathrm{~mm}$ ), unless stated otherwise, equilibrated with $150 \mathrm{mM} \mathrm{NaCl}, 50 \mathrm{mM}$ sodium phosphate buffer at $\mathrm{pH}$ 7.5. When mentioned, reducing agent (1 mM Tris(2carboxyethyl)phosphine, TCEP) was added to the buffer. The column was calibrated with six globular proteins of different molecular mass: thyroglobulin, ferritin, alcohol dehydrogenase, conalbumin, ovalbumin and carbonic anhydrase. Throughout elution, the absorbance at $280 \mathrm{~nm}$ was monitored to determine the presence of proteins. The fractions were collected, concentrated (spin $\mathrm{X}$-UF ultra centrifugal concentrator, Corning, $5 \mathrm{kDa}$ cutoff) and stored at $-20^{\circ} \mathrm{C}$.

\section{Circular dichroism (CD)}

$10 \mu \mathrm{M}$ CP12 without histidine tag in $50 \mathrm{mM}$ sodium phosphate $\mathrm{pH} 6.5$ was used to record CD spectra (Jasco $815 \mathrm{CD}$ spectrometer, $2 \mathrm{~mm}$ thick quartz cells) scanned from 190 to $260 \mathrm{~nm}$ at a speed of $10 \mathrm{~nm} / \mathrm{min}(\mathrm{n}=3)$. The data were analyzed using Dichroweb using the CDSSTR, SELCON3 and CONTIN analysis programs, and the reference set 7 (http://dichroweb.cryst.bbk.ac.uk/html/ home.shtml) [40, 41] and Bestsel (http://bestsel.elte.hu/ index.php) [42].

\section{Nuclear magnetic resonance (NMR)}

${ }^{15} \mathrm{~N}$-labelled histidine tagged CP12 were produced using the enhanced M9 medium (protocol of the European Molecular Biology Laboratory, https://www.embl.de/ pepcore/pepcore_services/protein_expression/ecoli/ n15/index.html) and purified as described above. The final sample was buffer exchanged in $50 \mathrm{mM}$ sodium phosphate $\mathrm{pH} 6.5,50 \mathrm{mM} \mathrm{NaCl}, 10 \% \mathrm{D}_{2} \mathrm{O}$ with traces of sodium trimethylsilylpropanesulfonate (DSS) and at a final protein concentration of $250 \mu \mathrm{M}$.

The data were recorded at $4{ }^{\circ} \mathrm{C}$ and $15{ }^{\circ} \mathrm{C}$. Fast ${ }^{1} \mathrm{H}$ -

${ }^{15} \mathrm{~N}$ heteronuclear single quantum correlation (fHSQC [43]) spectra were recorded with a ${ }^{1} \mathrm{H}$ acquisition time of $243 \mathrm{~ms},{ }^{15} \mathrm{~N}$ acquisition time of $42 \mathrm{~ms}$ and with 24 scans on a $600 \mathrm{MHz}$ NMR spectrum equipped with a cryogenic probe (Bruker). Translational diffusion was measured using standard bi-polar stimulated echo experiment [44], with a diffusion delay $(\Delta)$ of $200 \mathrm{~ms}$. Ten experiments were recorded in which the encoding and decoding pair of gradients are produced with squared $1.4 \mathrm{~ms}$ long gradients $(\delta)$ with strength $(\mathrm{G})$ ranging from 2 to $98 \%$ of the maximum gradient strengths $\left(5.1 \mathrm{G} \mathrm{mm}^{-1}\right)$. The data were processed using nmrPipe [45], plotted using Sparky[46]. The diffusion coefficient (D) was calculated using Octave [47] from the integral of proton signals of the methyl side chains of the protein from 1.2 to $0.7 \mathrm{ppm}$. The linear dependency of the logarithm of the integral as a function of the gradient strength was used to determine D as follows:

$$
\ln \left(\frac{I_{G}}{I_{0}}\right)=D \cdot\left[\Delta-\frac{\delta}{3}\right] \cdot\left(\delta \cdot G \cdot \gamma_{H}\right)^{2}
$$

where $I_{G}$ is the integral as a function of the gradient strength, $I_{0}$ is the integral in the absence of gradient, $\gamma_{H}$ is the proton gyromagnetic ratio, and $\Delta, \delta$ and $\mathrm{G}$ are defined above. The hydrodynamic radius associated with the diffusion coefficient was determined using the Stokes-Einstein equation:

$$
r_{H}=\frac{k_{B} \cdot T}{6 \pi \cdot D \cdot \eta_{(T)}}
$$

where $\mathrm{k}_{\mathrm{B}}$ is the Boltzmann constant, $\mathrm{T}$ the temperature in Kelvin and $\eta_{(T)}$ the viscosity.

\section{Size-exclusion chromatography coupled to small angle X-ray scattering (SEC-SAXS)}

SEC-SAXS experiments were performed on SWING beamline at the SOLEIL synchrotron using the online HPLC size exclusion chromatography facilities [48]. The sample-to-detector (CCD Aviex) distance was set at $2 \mathrm{~m}$, leading to scattering vectors $(\mathrm{q}=4 \pi / \lambda \sin \theta$, where $2 \theta$ is the scattering angle and $\lambda$ the wavelength, equal to $1.033 \AA$ ) ranging from 0.01 to $0.46 \AA$. $50 \mu \mathrm{L}$ of His-tagged CP12 $(11 \mathrm{mg} / \mathrm{mL})$ were injected into a pre-equilibrated size exclusion chromatography column (Agilent BioSEC-3300 A) upstream of the measurement capillary at a temperature of $15^{\circ} \mathrm{C}$. Frames of 990 ms with dead-time of $10 \mathrm{~ms}$ were recorded throughout the elution, with 100 frames recorded at the very first minutes of the elution to measure the buffer background. The protein concentration was monitored via the absorbance at $280 \mathrm{~nm}$ with an in situ spectrophotometer. The experiment was performed in $30 \mathrm{mM}$ Tris, $50 \mathrm{mM} \mathrm{NaCl}, 2 \mathrm{mM}$ EDTA, $1 \mathrm{mM}$ TCEP, pH 7.5.

Data reduction to absolute units and solvent subtraction were performed using FOXTROT, a dedicated in-house application. The frames recorded during the elution peak were carefully compared with each other, and data corresponding to identical scattering profiles and radius of gyration $(\mathrm{Rg})$ were averaged to increase the 
signal-to-noise ratio. Data analysis was performed using the ATSAS suite of software [49]. The Rg and forward scattering intensity I(0) were obtained via PRIMUS using the Guinier approximation up to $\mathrm{q} \cdot \operatorname{Rg}<1.0$, and the distance distribution function $\mathrm{P}(\mathrm{r})$ was obtained via GNOM. The molecular mass of CP12 was determined using the forward scattering intensity $\mathrm{I}(0)$ of the frame corresponding to the top of the peak, at the highest protein concentration as described in [50]. Ab initio models of 3D envelopes corresponding to the scattering curve were constructed using DAMMIF (10 runs) and GASBOR (5 runs) with P1 and P2 symmetry [49].

\section{D-modelling}

3D-modelling of the coiled coil domain has been performed using Swiss-model (https://swissmodel.expasy. org/ [51]) on a sequence including 5 residues before and 6 residues after the predicted coiled coil sequence highlighted in bold (APIVDSEYEAKVKSLSQMLTKTKAELDQVKALADDLKGVKLASPSV), without any other input. The model was fitted manually in the shape determined by SAXS.

\section{Results}

\section{Expression of a CP12 protein in T. pseudonana}

Chen et al. [29] reported a hypothetical protein of uncharacterized function that was overexpressed when $T$. pseudonana cells were limited by N, P or Si (identification: XP_002286772). This protein is identical to our previously identified CP12 protein that is expressed under low $\mathrm{CO}_{2}$ condition [28]. Our western-blot analysis indicates that CP12 protein was present in both dark-treated and light-treated T. pseudonana cells (Fig. 1a). Similarly, the expression level was stable during all phases of growth (Fig. 1b).

\section{In silico analysis of CP12 sequences}

The sequence of this CP12 protein was aligned with other representative CP12 sequences from the angiosperms A. thaliana, Pisum sativum and Spinacia oleracea, the green alga $C$. reinhardtii, two red algae Cyanidioschyzon merolae and Galdieria sulphuraria, and the cyanobacterium S. elongatus (PCC 7942) (Fig. 2). Beside the highly conserved AWD_VEEL motif, one pair of cysteine residues at the C-terminus, another hallmark for CP12s, was also present. In contrast, the highly conserved proline positioned at the center of the 8-residues linker between these two cysteine residues is absent in CP12 from $T$. pseudonana. In the nuclear genome of other diatoms, Phaeodactylum tricornutum, Thalassiosira oceanica, Fragilariopsis cylindrus and Pseudo-nitzschia multistri$a t a$, a gene encoding a protein with high similarity with this CP12 protein was also found (Fig. 2). Furthermore, all these newly identified CP12 proteins from diatoms were predicted to be addressed to the chloroplast, in good agreement with the known localization of CP12 in other well-studied organisms.
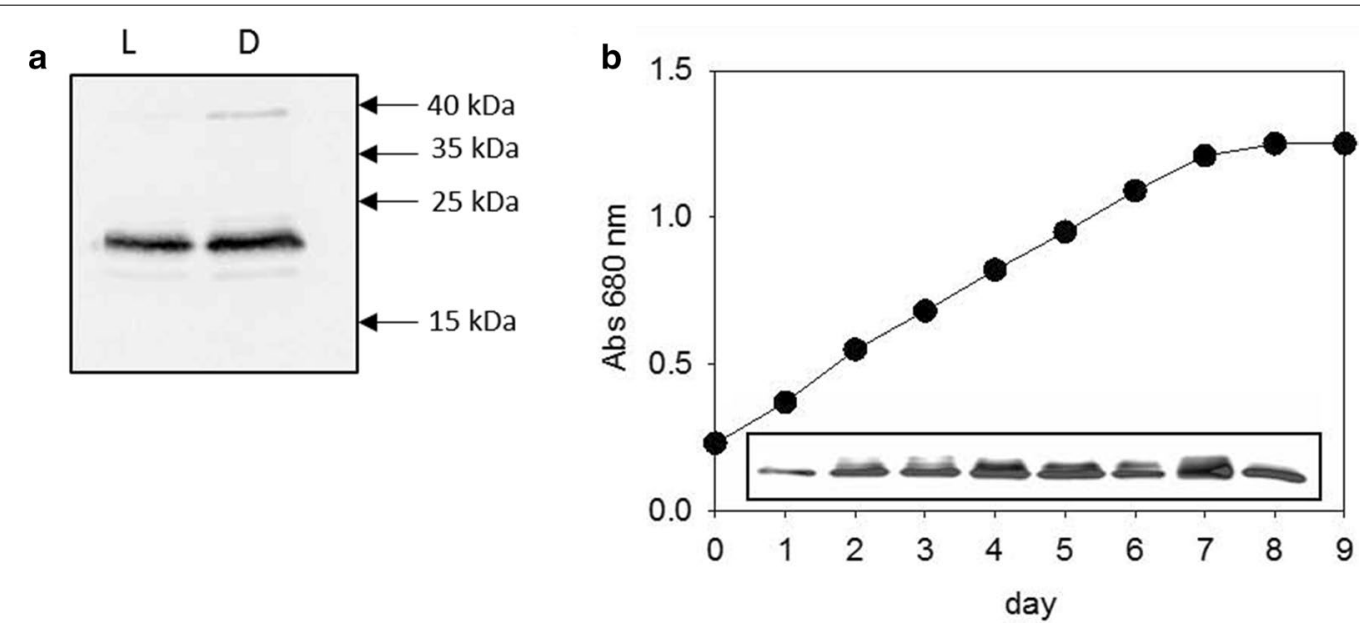

Fig. 1 Western blot of CP12 expression. a Dark and light conditions. $20 \mu \mathrm{g}$ crude extract from T. pseudonana cells grown under light (lane L) or dark (lane D). Molecular mass markers are shown on the right. After electrophoresis, the 12\% SDS-gels are transferred onto nitrocellulose membranes and revealed with enhanced chemiluminescence with $\mathbf{a}-$ T. pseudonana CP12 antibodies 1:10,000. b Expression during the different phases of the growth curve. The growth of T. pseudonana in $\mathrm{F} / 2+\mathrm{Si}$ medium, under continuous light and with air-concentration of $\mathrm{CO}_{2}(400 \mathrm{ppm})$ is followed by the absorbance at $680 \mathrm{~nm} .30 \mu \mathrm{g}$ of proteins from day 1 to 8 are loaded on SDS-PAGE gel. Proteins were transferred to a nitrocellulose membrane and revealed with antibodies raised against $\mathrm{Q}-\mathrm{T}$. pseudonana CP12 antibodies 


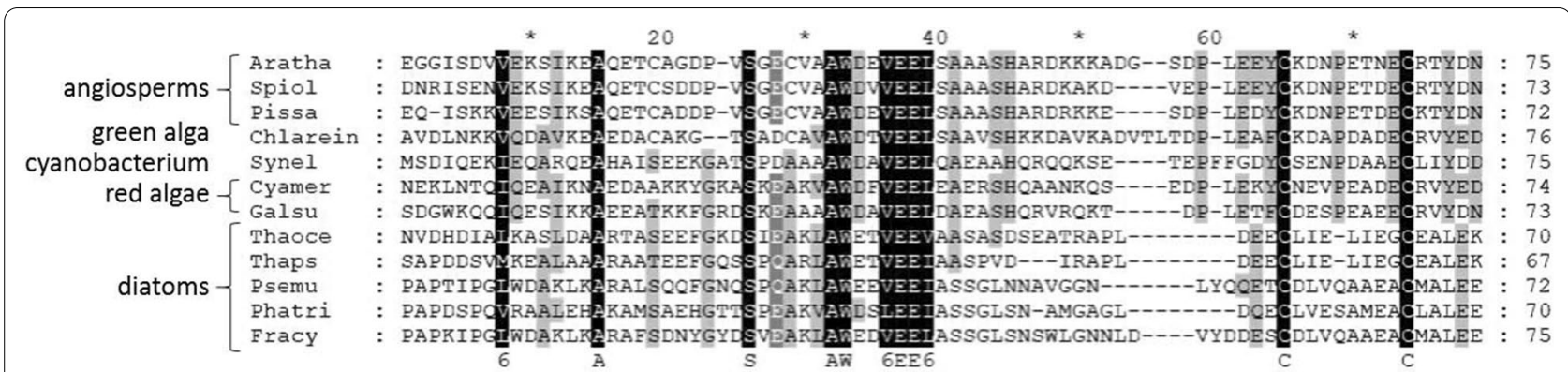

Fig. 2 Alignment of CP12-like protein sequences from different species. Only partial sequences are shown. Species and protein IDs are the following: Aratha, A. thaliana (protein ID: NP_191800.1-NCBI, 131 aa); Spiol, Spinacia oleracea (protein ID: CAA96568.1-NCBI, 124 aa); Pissa, Pisum Sativum (protein ID: CAA96570.1-NCBI, 127 aa); Chlarein, Chlamydomonas reinhardtii (protein ID: XP_001694345.1-NCBI, 107 aa); Synel, Synechococcus elongatus (protein ID: Q6BBK3-UniProt, 75 aa); Cyamer, Cyanidioschyzon merolae (protein ID: BAM82525.1-NCBI, 122 aa); Galsu, Galdieria sulphuraria (protein ID: CAI34858.1-NCBI, 129 aa); Thaoce, Thalassiosira oceanica (protein ID: 95994-JGI, 165 aa); Thaps, T. pseudonana (protein ID: EED96413.1-NCBI, 197 aa); Psemu, Pseudo-nitzschia multistriata (protein ID: 292992-JGI, 256 aa); Phatri, Phaeodactylum tricornutum (protein ID: 44297-JGI, 329 aa); Fracy, Fragilariopsis cylindrus (protein ID: 244965-JGl, 234 aa). Alignments were performed with ClustalW, using MEGA7 software, and the figure was processed with GeneDoc (http://www.nrbsc.org/gfx/genedoc) with similar residues shaded using the conservation mode. The signal peptides are not included in the alignment

\section{In silico characterization of the propensity of disorder}

Since CP12 proteins from other organisms are IDPs [10, 12, 52], we checked whether CP12 from T. pseudonana was likely to contain disordered regions. The amino acid composition of this $\mathrm{CP} 12$ and that from $C$. reinhardtii, a well-known IDP, were compared to globular proteins. In the sequences of CP12 from C. reinhardtii and T. pseudonana, alanine (A) and charged residues that promote disorder such as aspartate, glutamate and lysine residues (D, $\mathrm{E}$ and $\mathrm{K})$, are more abundant than in globular structured proteins (Fig. 3a). In contrast, order-promoting residues such as tryptophan, phenylalanine and tyrosine residues (W, F and Y) are less abundant than in structured proteins. In CP12 from T. pseudonana, cysteine residues are less abundant (two cysteine residues) than in the green algal CP12 (four cysteine residues).

It has an isoelectric point of 4.5 like many proteins, and interestingly, a very high negative net charge -14.6 strengthening the hypothesis that this protein contains disordered regions.

The disorder propensity of CP12 from T. pseudonana was predicted using several algorithms. PONDR predicted a long disordered segment between residues 81-146, whereas the other predictors were more stringent (Fig. 3b), in particular IUPred2A which predicts only a small number of disordered regions. Taking all predictions together, four regions of disorder were consensually predicted which encompass residues 30-42, 77-93, 108117 and 129-139 (shaded residues in Fig. 3b). Apart from the disordered regions, the algorithm s2D predicts the other regions to have a high propensity to form helices.

\section{Experimental characterization of the propensity of disorder}

Abnormal migration is often observed in SDS-PAGE for IDPs, with an apparent molecular mass higher than the theoretical one. The theoretical molecular mass of a monomer of CP12 from T. pseudonana is $17.6 \mathrm{kDa}$ but it migrated as a protein of higher molecular mass of about $22 \mathrm{kDa}$ in SDS-PAGE (Fig. 1a). This abnormal migration resembles that of $\mathrm{CP} 12$ from $C$. reinhardtii where the molecular mass of the monomer with a histidine tag is $\sim 11 \mathrm{kDa}$ but migrates at about $20 \mathrm{kDa}$ [8].

\section{Oligomeric state of CP12}

Oligomeric state of CP12 was investigated using native ESI-MS. Monomeric and dimeric forms were observed (Fig. 4a). Experimental deconvoluted values of 17,642.1 $( \pm 0.5) \mathrm{Da}$ and $35,285.3( \pm 0.7)$ Da fit well with theoretical values for the monomeric and dimeric species, 17,641.8 Da and 35,283.6 Da respectively. Under size exclusion chromatography, a single and narrow elution peak was observed, even at very low protein concentration, suggesting a unique oligomeric state in solution (Fig. 4b). This oligomeric state is not due to a covalent bond through the cysteine residues, because size exclusion chromatography showed the same single elution peak both in the presence and in the absence of reducing agent (Additional file 1: Figure S1a). Upon addition of the Ellman's reagent, DTNB, the absorbance at $412 \mathrm{~nm}$ immediately reached a value corresponding to two free thiol groups in recombinant CP12 from T. pseudonana. This result indicates that its two cysteine residues were not involved in either an intra- or inter-molecular disulfide bridge, even under atmospheric aerobic 

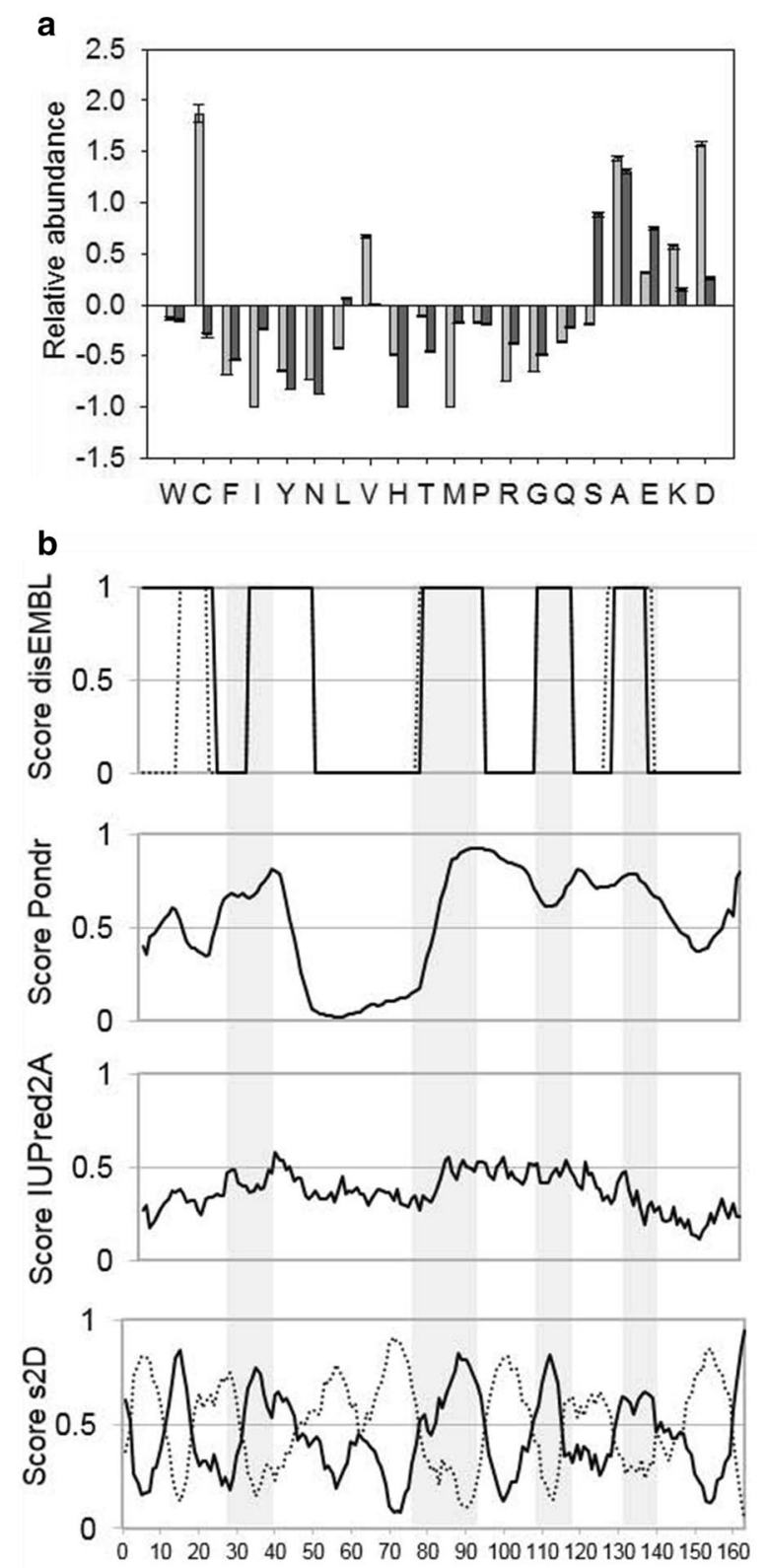

Residue number

Fig. 3 In silico analysis of CP12. a Amino acid composition of CP12s. The abundance of amino acids of both T. pseudonana CP12 (black bars) and C. reinhardtii CP12 (grey bars) were compared against proteins from the PDB database using Composition Profiler (http:// www.cprofiler.org/cgi-bin/profiler.cgi). b Prediction of disordered region. The sequence on the $x$-axis is numbered according to the protein without tag and starting at AAIEAA. The residues propensity to be in a disordered region is shown as a score varying from 0 to 1, and these are predicted using, from top to bottom: disEMBL (for hot loop, in continuous line and for coil, in dotted line), PONDR-FIT, IUPred2A and s2D (continuous line). For most residues, s2D also predicts a significant propensity to form a-helices shown with dotted line conditions. In addition, immediate titration of the thiol groups suggests that the cysteine residues are not buried and are readily accessible to the reagent. The two oligomeric forms observed by ESI-MS can be ascribed to a partial dissociation of the dimer during ionization of the molecular complex. This dissociation of the dimer further supports that it is not a covalent dimer. Finally, the discrepancy between the molecular mass determined by ESI-MS for the dimeric state and the size exclusion chromatography elution volume of CP12 (corresponding to an apparent molecular mass of $93( \pm 4) \mathrm{kDa})$ suggests that CP12 is an extended dimer.

\section{CP12 is a dynamic extended dimer}

The hydrodynamic size of CP12 in solution was confirmed by measuring the translational diffusion coefficient using DOSY-NMR (Fig. 5a). The translational diffusion coefficient was $3.8( \pm 0.1) 10^{-11} \mathrm{~m}^{2} \mathrm{~s}^{-1}$ at $4{ }^{\circ} \mathrm{C}$, which corresponds to a homogeneous species with a hydrodynamic radius $(\mathrm{Rh})$ of $3.4( \pm 1) \mathrm{nm}$. For a folded dimer of $35.3 \mathrm{kDa}$, the theoretical $\mathrm{Rh}$ is $2.75 \mathrm{~nm}$, while for an unfolded dimer it is $5.94 \mathrm{~nm}$ [53]. Therefore, the experimental $\mathrm{Rh}$ of $3.4 \mathrm{~nm}$ represents an intermediate between that expected for a fully disordered and a fully ordered dimer and is also compatible with an extended dimer.

${ }^{1} \mathrm{H}-{ }^{15} \mathrm{~N}$ fast-HSQC spectrum of $\mathrm{CP} 12$ presents some characteristic features of that of a disordered protein with the absence of ${ }^{1} \mathrm{H}$ chemical shift dispersion (Fig. 5b). 34 resonances present narrow linewidths compatible with a purely disordered region. However, in contrast to true random-coil proteins such as $\mathrm{CP} 12$ from $C$. reinhardtii (Fig. 5c, [10]), the linewidths of the observed resonance varied from narrow $(<20 \mathrm{~Hz})$ to broad $(>60 \mathrm{~Hz})$, indicating the presence of an intermediate chemical exchange on the NMR timescale. This result suggests that reduced CP12 is highly dynamic on a range of timescale from ps to $\mathrm{ms}$ and does not possess a stable secondary structure.

We then performed SEC-SAXS experiment on CP12 to assess the overall structure and oligomeric state of disordered or partly disordered proteins (Fig. 6) [50]. The Guinier plot of the average spectrum was linear with a slight increase at very small $\mathrm{q}\left(\mathrm{q}<0.14 \AA^{-1}\right)$, indicating the presence of very small traces of aggregates that were not detected by the absorbance at $280 \mathrm{~nm}$ (Fig. 6b). The molecular mass inferred from the forward scattering intensity, independently of the shape of the protein, is $41.5( \pm 3.0) \mathrm{kDa}$, confirming that $\mathrm{CP} 12$ is dimeric, as the theoretical molecular mass of dimeric histidine-tagged $\mathrm{CP} 12$ is $39 \mathrm{kDa}$. The inferred radius of gyration of CP12 was $38.2( \pm 0.4) \AA$. The maximum dimension of the protein was $135( \pm 5) \AA$, indicating that the protein is elongated. The normalized Kratky plot exhibited a large peak 

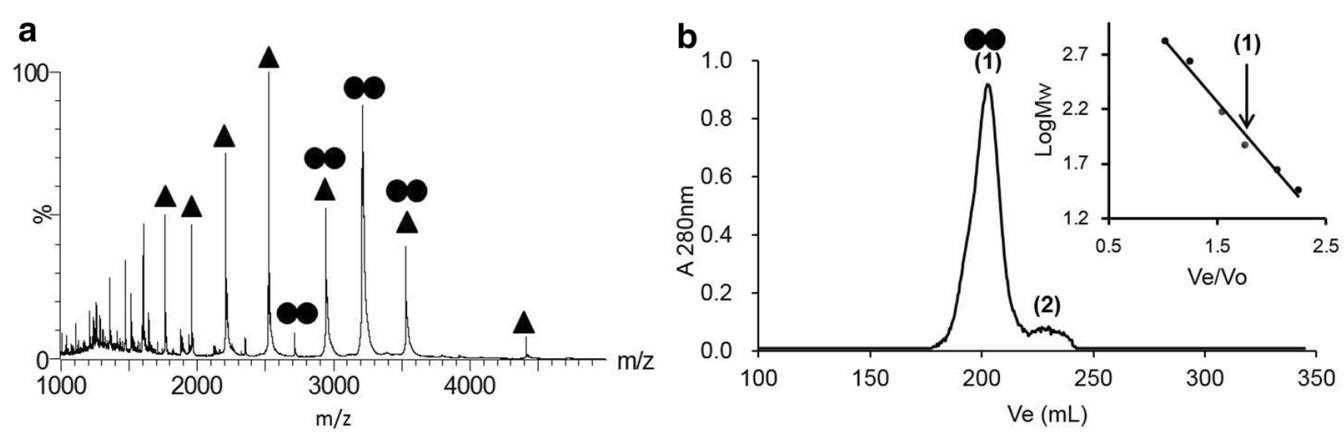

Fig. 4 Oligomerization of CP12 revealed by native ESI-MS and size-exclusion chromatography. a ESI-MS spectrum of CP12. Signals labelled with a single triangle are assigned to monomeric CP12 (envelope of $\mathrm{m} / \mathrm{z} 1765.2$ to 4411.4 with charged states ranging from 10 to 4 ), and signals labelled with two circles are assigned to dimeric CP12 (envelope of m/z 2715.1 to 3529.4 with charged states ranging from 13 to 10 ). $\mathbf{b}$ Elution profile of CP12 on a S200 size-exclusion column. The single elution peak is assigned to dimeric CP12 (labelled with (1)). A small proportion of a smaller particle is assigned with the labelled (2) and is ascribed to impurities. The column was calibrated with proteins of known relative molecular mass (insert): Thyroglobulin (670 kDa), Ferritin (440 kDa), Alcohol dehydrogenase (150 kDa), Conalbumin (75 kDa), Ovalbumin (44 kDa), carbonic anhydrase $(30 \mathrm{kDa})$. The linear fit $\left(\mathrm{R}^{2}=0.98\right)$ indicates a dependency of the $\mathrm{MW}$ as a function of the elution volume $(\mathrm{Ve})$ as: $M W=10^{-1.16 \frac{\mathrm{Ve}}{\mathrm{Vo}}+4} \mathrm{with}$ Vo being the elution volume of blue dextran (void volume of $110.3 \mathrm{~mL}$ ). The elution volume of CP12 is indicated with an arrow
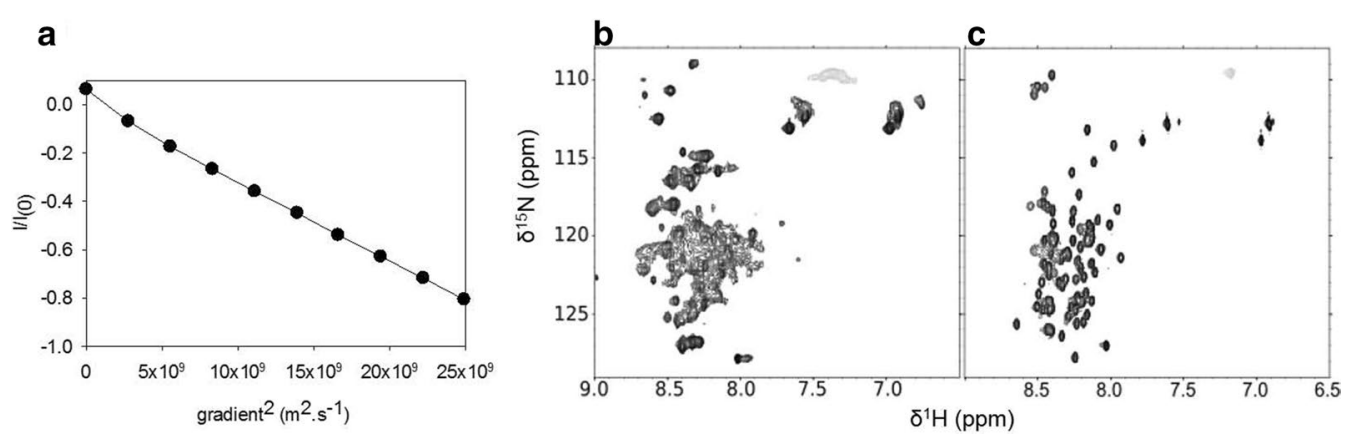

Fig. 5 NMR spectrometric characterization of CP12: a dynamic dimer. a DOSY-NMR analysis of CP12, on the $x$-axis is the gradient strength and on the $y$ axis is the normalized intensity on a In scale (refer to Material and methods section). A linear dependency indicates a homogenous oligomerization of the protein. The linear fit indicates a diffusion coefficient of $3.8( \pm 0.1) 10^{-11} \mathrm{~m}^{2} \mathrm{~s}^{-1}$, which relates to a hydrodynamic radius (Rh) of $3.4( \pm 1) \mathrm{nm}$. $\mathbf{b}$ and $\mathbf{c}$ show the ${ }^{1} \mathrm{H}-{ }^{15} \mathrm{~N}$ fHSQC spectra of CP12 from T. pseudonana and C. reinhardtii [10] respectively

at $(\mathrm{q} \cdot \operatorname{Rg})=3.4$ and $(\mathrm{q} \cdot \mathrm{Rg})^{2} \cdot \mathrm{I}(\mathrm{q}) / \mathrm{I}(0)=1.7$, followed by a decrease and then an increase of the curve, and is typical of a protein containing both globular folded domain(s) and disordered region(s) (Fig. 6a) [50]. Determination of the envelope of CP12 gave similar results using DAMMIF or GASBOR, applying a P1 or P2 symmetry, with excellent fits to the data $\left(x^{2}=1.61-1.66\right.$ with DAMMIF, and $1.39-2.39$ with GASBOR, Fig. $6 \mathrm{~b})$. The envelope is very elongated and forms a cylinder of $\sim 20-25 \AA$ diameter, with several kinks which may reflect the limits between different domains (Fig. 6c). This is also consistent with the presence of several disordered regions as previously mentioned (Fig. 3b).

\section{Secondary structure of $\mathrm{CP} 12$}

Circular dichroism (CD) was used to determine the secondary structure of CP12. The CD spectrum had two minima at 208 and $222 \mathrm{~nm}$ (Fig. 7), and its deconvolution reveals a high content of $\alpha$-helices (from 32 to $50 \%$ ), plus $10 \%$ of $\beta$-sheets and from 27 to $48 \%$ of random coil (Additional file 1: Table S1). This result is consistent with the prediction of both disordered and helical regions using the $\mathrm{s} 2 \mathrm{D}$ predictor. To investigate further the conformation of $\mathrm{CP} 12$, the solvent 2,2,2-trifluoroethanol (TFE), known to stabilize helical structures, was added. The CD spectra with increasing TFE concentrations showed an increase of the content of $\alpha$-helices up to $79 \%$, as revealed by lower values of ellipticity at 208 and $222 \mathrm{~nm}$. We observed an isosbestic point at 201-202 nm, indicating the existence of two conformers in equilibrium (Fig. 7a). The presence of unstable helical structures in a 


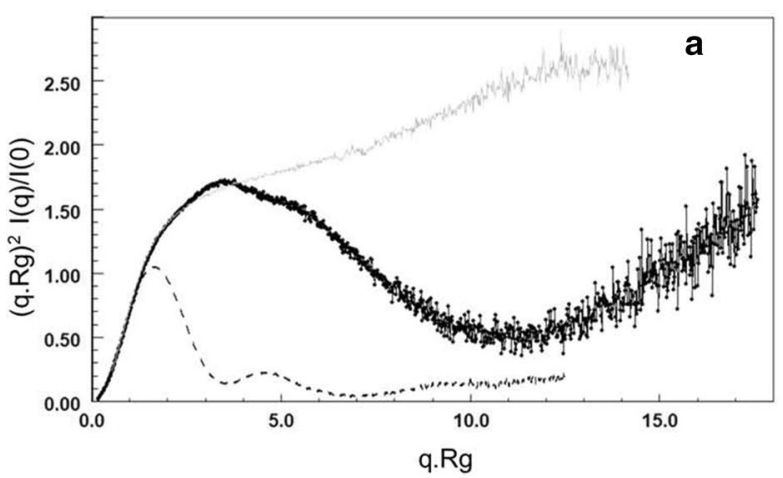

\section{C}
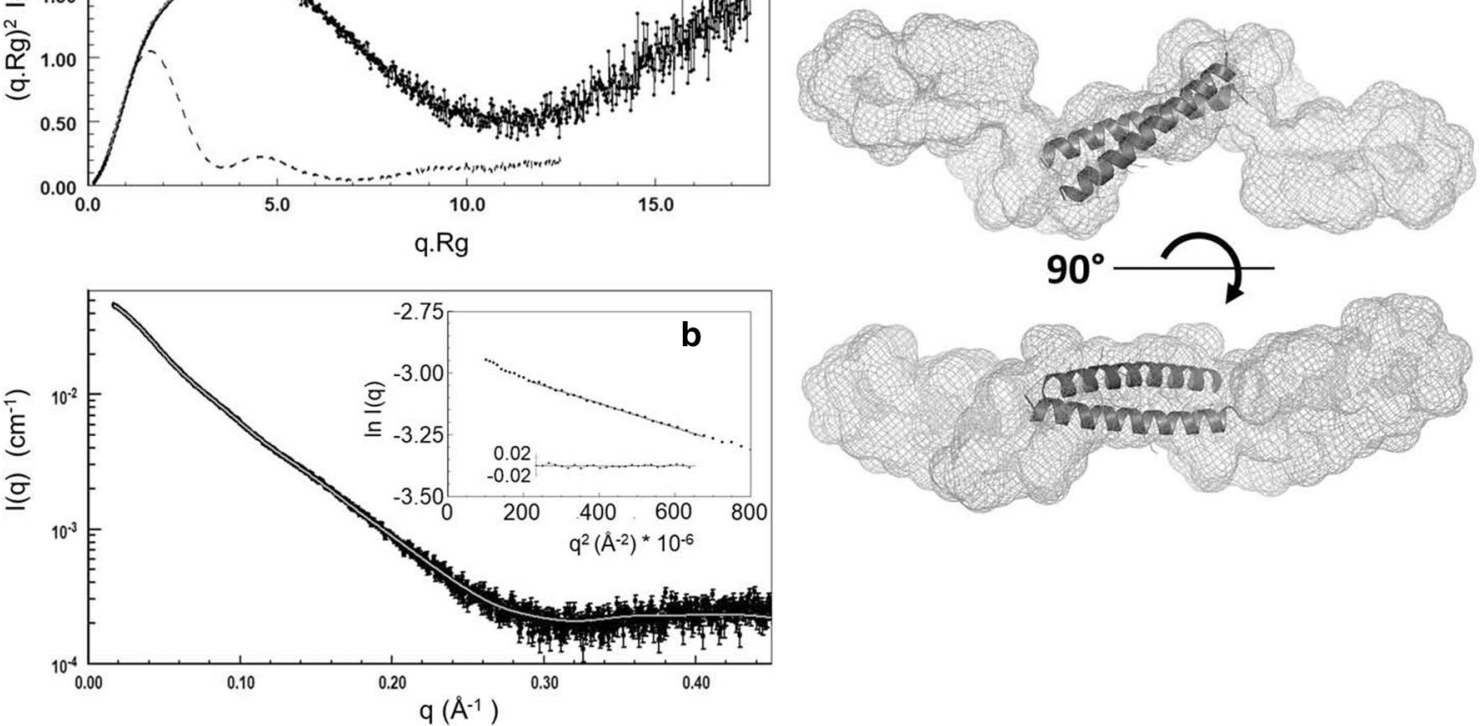

Fig. 6 SAXS characterisation of CP12: an extended dimer. a Normalized and dimensionless Kratky plot. The data for T.pseudonana CP12 is shown in black, and can be compared with that for a fully disordered protein (C. reinhardtii reduced CP12 [10]), in grey, and that for a globular protein (C. reinhardtii GAPDH [1 1]) with dotted line. $\mathbf{b}$ Scattering intensity for CP12 (black) as a function of $\mathrm{q}(4 \pi / \lambda \sin \theta$ ) overlaid with the DAMMIF fit (grey) related to the shape shown in $\mathbf{c}$. The coiled coil structure calculated by Swiss-Model is inserted in the SAXS envelope (c). The insert in $\mathbf{b}$ shows the Guinier plot together with the residuals
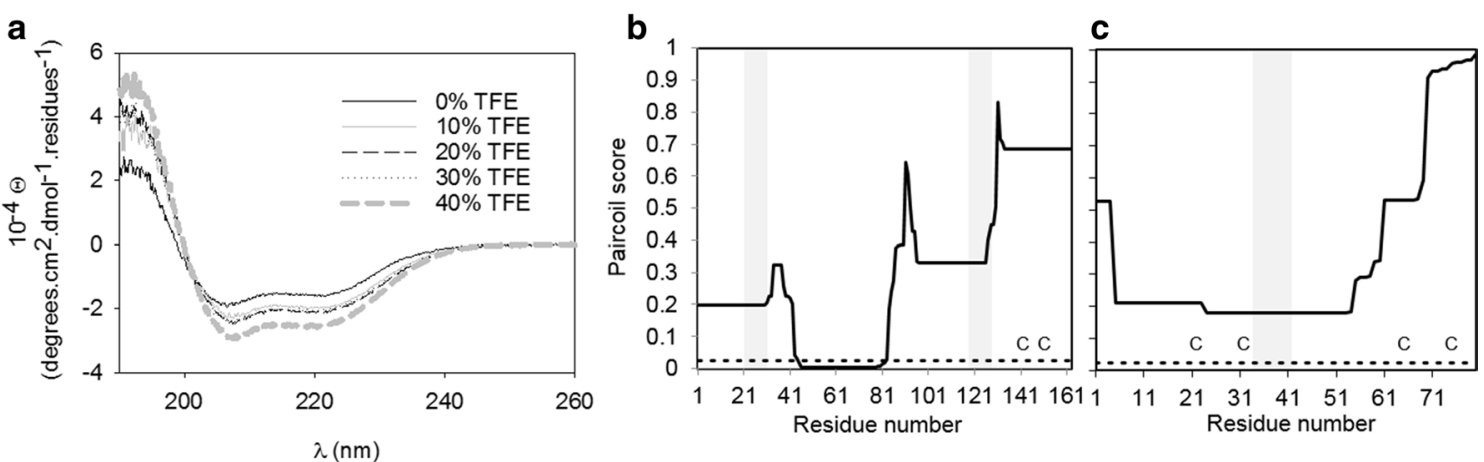

Fig. 7 CD characterisation of CP12: high helical content and putative coiled coil arrangement. a CD spectra of $10 \mu \mathrm{M}$ CP12 in 50 mM phosphate buffer $\mathrm{pH} 6.5$ with increasing concentration of TFE. These spectra indicate a high proportion of helical structure, which increases further in the presence of TFE. b, c Result of the Paircoil predictor for the search of putative coiled coil motif for each T. pseudonana CP12 residues (b) and C. reinhardtii CP12 residues (c). The coiled coil prediction is shown as a score varying from 0 to 1 (a score of 0 indicates a high probability to be in a coiled coil region and in contrast a score of 1, a low probability). The threshold for a region to have a high probability to form a coiled coil structure is indicated with a dotted line (score $<0.025)$. The AWD_VEEL regions are highlighted in grey, and the position of the cysteine residues are indicated with a C

dimeric and elongated protein is reminiscent of a coiled coil propensity, we thus used a predictor for coiled coil regions and found that the region encompassing residues
46-82 (Fig. 7b) has a very high propensity for coiled coil arrangement. Furthermore, 3-D modelling of this domain using Swiss-Model yielded a dimeric coiled coil structure 
which can be accommodated into the central region of the SAXS envelope (Fig. 6c). The propensity to form coiled coil structures might be a characteristic shared with other CP12 proteins, and at least CP12 from C. reinhardtii has a weak propensity to form coiled coil in the region encompassing the AWD_VEEL motif (Fig. 7c). These in silico predictions are consistent with our experimental data; in particular the SAXS results are consistent with a putative central coiled coil domain flanked by other elongated domains likely to be disordered and/or possibly containing short structural elements.

\section{Discussion}

CP12 proteins from different organisms are highly diverse at the protein sequence level [2] but have some characteristic features such as the AWD_VEEL motif and often a pair of cysteine residues, at the $C$ terminus, separated by eight residues encompassing a proline residue. The CP12 proteins from $C$. reinhardtii, A. thaliana and S. elongatus have been extensively studied and shown to belong to the IDP family. IDPs, or in other words ductile, dancing, malleable or flexible proteins [54], are common in various proteomes [55-60] and occupy a unique structural and functional niche in which function is directly linked to structural disorder [52, 61-63]. The absence of structure has been proposed to be a significant advantage for proteins whose functions are related to stress response [64], as e.g. in the oncologic context [65]. Furthermore, protein structural disorder is an asset with respect to fluctuating environmental conditions as faced by diatoms [52]. The dynamic structural properties of CP12 proteins could similarly confer them functional advantage, and indeed, some of their functions are related to oxidative stress response in higher plants [18, $19,21]$.

T. pseudonana CP12 is indeed more expressed under all tested stress-related conditions (nutrient deprivation [29], low $\mathrm{CO}_{2}$ [28]), suggesting that CP12 is involved in a broad range of metabolisms. Only 37 proteins, including $\mathrm{CP} 12$, among 1111 proteins differentially expressed in three macronutrients deficient $(\mathrm{Si}, \mathrm{P}, \mathrm{N})$ cells, are more abundant in all these stresses [29]. As such, CP12 can be considered as a stress protein, since stress proteins are a diverse group of proteins that are synthesized at increased levels under a variety of stressful stimuli, and have a protective effect against the stress. We speculate that its dynamical properties that we describe in this study are related to this function.

Besides, in this study, we show that the expression of CP12 from the diatom T. pseudonana is constitutively expressed under dark and light conditions, as well as during the growth, unlike CP12 from $A$. thaliana that is co-expressed with PRK and GAPDH in the light [66].
In contrast in this diatom, while $\mathrm{CP} 12$ is upregulated in stress conditions, GAPDH and PRK are downregulated [29], and this indicates that CP12 may have other functions in diatoms compared to viridiplantae.

Like CP12 from other organisms [8, 12, 55], CP12 from T. pseudonana is characterized by several features of IDPs, with a lower proportion of order-promoting residues and a higher proportion of charged residues than structured proteins. This high net charge and low overall hydrophobicity is concordant with the absence of rigid globular core as observed using NMR and with its high flexibility on the NMR-timescale. Another IDP characteristic is the ability to be involved in the formation of macromolecular complex, and this is the case for CP12 proteins from other organisms that bind to GAPDH and PRK $[8,9,18,67-69]$. In contrast, the PRK-GAPDHCP12 ternary complex has not been found in diatoms. This was attributed to the absence of cysteine residues on PRK in diatoms [25] but may also be the consequences of specific features of this CP12. Moreover, in a freshwater diatom, Asterionella formosa, GAPDH interacts with the ferredoxin-NADP reductase (FNR), from the primary phase of photosynthesis, and a small protein identified as a CP12 [70]. Diatom chloroplasts lack the oxidative pentose phosphate pathway, the main NADPH generating source in the dark. In the ternary complex GAPDHCP12-FNR, GAPDH, a main NADPH consumer, is inhibited [23], thereby releasing the pressure on NADPH availability for other metabolic pathways.

While CP12 from T. pseudonana is predicted to contain at least a long disordered region, the proportion of $\alpha$-helices in CP12 from T. pseudonana $(50 \%)$ is much higher than in CP12 from $C$. reinhardtii [11] $(30 \%)$ and in canonical IDPs. In addition, SEC-SAXS and native ESI-MS showed that CP12 from T. pseudonana is dimeric unlike CP12 from other species where it is monomeric in its free isolated state [10-12]. This dimeric state is homogeneous in solution as shown by SEC and DOSY-NMR, and is induced neither by formation of a disulfide bridge, nor by the presence of the His-tag (Additional file 1: Figure S1b). Dimeric oligomerization of very dynamic proteins is mediated by numerous but transient inter-molecular interactions, and this is a feature of coiled coil arrangement [71-73]. Indeed besides long disordered regions, CP12 from $T$. pseudonana is also predicted to contain a region that has a high probability to form coiled coils, and this is consistent with the extended hydrodynamic radius experimentally observed by gel filtration and DOSYNMR, and with the global shape derived from the SAXS data (Fig. 6c). Coiled coil is an omnipresent protein fold, accounting for about $3-10 \%$ of all proteincoding regions across all genomes [74-76]. Proteins 
having coiled coils are highly dynamic and contribute to an ever-growing list of functional contexts [71-73] and coiled coils are one of the most ubiquitous protein-protein interaction motifs [75]. Although CP12 from C. reinhardtii is not predicted to form coiled coil structures with the same high probability as T. pseudonana CP12, they both share a propensity to form unstable helices [11]. Such highly dynamic and adaptative biophysical properties is a common feature of moonlighting proteins [13].

\section{Conclusion}

The structural properties of CP12 from T. pseudonana, with putative dimeric coiled coil domain and disordered regions, suggest that it is not an alien as regard to other CP12s and might therefore have one-to-many functions. As the gene encoding this protein has also been found in other diatoms, it could be another facet of the enigmatic regulation of diatom metabolism [22, $26,77]$. These findings extend the context for dynamic and coiled coil proteins related to their functions in photosynthesis regulation and stress in diatoms.

\begin{abstract}
Abbreviations
CBB: Calvin-Benson-Bassham; CD: Circular dichroism; CP12: Chloroplast Protein of $12 \mathrm{kDa}$; DOSY-NMR: Diffusion ordered spectroscopy-nuclear magnetic resonance; DTNB: 5,5'-Dithiobis-(2-nitrobenzoic acid); EDTA: Ethylenediaminetetraacetic acid; ESI-MS: Electrospray ionization-mass spectrometry; FNR: Ferredoxin-NADP reductase; GAPDH: Glyceraldehyde phosphate dehydrogenase; HSQC: Heteronuclear single quantum coherence; IDP: Intrinsically disordered protein; NMR: Nuclear magnetic resonance; PRK: Phosphoribulokinase; SAXS: Small angle X-ray scattering; SDS-PAGE: Sodium dodecyl sulfate polyacrylamide gel electrophoresis; SEC: Size exclusion chromatography; TCEP: Tris(2-carboxyethyl)phosphine; Tris: Tris(hydroxymethyl)aminomethane.
\end{abstract}

\section{Supplementary Information}

The online version contains supplementary material available at https://doi. org/10.1186/s12964-021-00718-x.

Additional file 1. Supplementary Figure 1. The oligomerisation of CP12 is independent of the His-tag and does not involve disulfide bond. a Normalised SEC profile of recombinant His-tagged CP12 with (red) and without (blue) $1 \mathrm{mM}$ TCEP recorded on a Superdex 200 Increase $10 \mathrm{~mm} \times$ $300 \mathrm{~mm}$. Under reducing condition, His-tagged CP12 was treated with 10 mM TCEP before injection onto the column. $b$ Normalised SEC profile of recombinant CP12 before (blue) and after His-tag removal (red) by thrombin, recorded on an Agilent Bio-SEC-3 300 Å column. Supplementary Table 1: Percentage of a-helices, strand, turn and other type of secondary structures of CP12 (included unstructured) derived from the CD profiles using different deconvolution methods: Bestsel, Dichroweb using the CDSSTR, SELCON3 and CONTIN methods and the reference set 7.

\section{Acknowledgements}

We thank S.C. Maberly for useful discussions and manuscript corrections. We thank O. Bornet for access and maintenance of the IMM NMR platform We acknowledge SOLEIL for provision of synchrotron radiation facilities, and we would like to thank the staff of the SWING beamline for assistance during the SAXS measurements.

\section{Authors' contributions}

$L A, V R-B, B G, H L$ conceived and planned the experiments. $H S$, WH, VR-B, $C P$ $R P, R L, H L, B G$ conducted the experiment. VR-B, RP, RL, HL, BG analysed the data. $B G, H L$ wrote the manuscript. All authors provided critical feedback on research, analysis and manuscript writing. All authors read and approved the final manuscript.

\section{Funding}

This work was supported by the CNRS. BG is supported by the Agence Nationale de la Recherche Grant ANR-15-CE05-0021-03. HL is supported by the A*MIDEX Grant AAP-IM2B-NE-2020-02-Launay. HS scholarship was founded by the Chinese Scholarship Council (201704910795). WH was supported by a fellowship for a visiting scholar from the Chinese Academy of Sciences.

Availabitility of data and materials

Not applicable.

\section{Declarations}

Ethical approval and consent to participate

Not applicable.

\section{Consent for publication}

Not applicable.

\section{Competing interests}

The authors declare that they have no competing interests.

\section{Author details \\ ${ }^{1}$ CNRS, BIP UMR 7281, Aix Marseille Univ, 31 Chemin Joseph Aiguier, 13402 Marseille Cedex 20, France. ${ }^{2}$ Key Laboratory of Aquatic Botany and Watershed Ecology, Wuhan Botanical Garden, Center of Plant Ecology, Core Botanical Gardens, Chinese Academy of Sciences, Wuhan 430074, China. \\ ${ }^{3}$ Centre for Enzyme Innovation, School of Biological Sciences, Institute of Bio- logical and Biomedical Sciences, University of Portsmouth, Portsmouth PO1 2DY, UK. ${ }^{4}$ CNRS FR 3479, Plate-Forme Protéomique de L'Institut de Microbiol- ogie de La Méditerranée (IMM), Aix Marseille Univ, 13009 Marseille, France.}

Received: 18 December 2020 Accepted: 9 February 2021

Published online: 24 March 2021

\section{References}

1. Pohlmeyer K, Paap BK, Soll J, Wedel N. CP12: a small nuclear-encoded chloroplast protein provides novel insights into higher-plant GAPDH evolution. Plant Mol Biol. 1996;32:969-78.

2. Groben R, Kaloudas D, Raines CA, Offmann B, Maberly SC, Gontero B. Comparative sequence analysis of CP12, a small protein involved in the formation of a Calvin cycle complex in photosynthetic organisms. Photosynth Res. 2010;103:183-94.

3. Stanley DN, Raines CA, Kerfeld CA. Comparative analysis of 126 cyanobacterial genomes reveals evidence of functional diversity among homologs of the redox-regulated CP12 protein. Plant Physiol. 2013;161:824-35.

4. López-Calcagno PE, Howard TP, Raines CA. The CP12 protein family: a thioredoxin-mediated metabolic switch? Front Plant Sci. 2014;5:9.

5. Gontero B, Avilan L, Lebreton S. Control of carbon fixation in chloroplasts. In: Plaxton WC, McManus MT, editors. Control prim metab plants. Oxford: Blackwell Publishing Ltd; 2006. p. 187-218. https://doi.org/10.1002/97804 70988640.ch7

6. Mcfarlane C, Shah N, Kabasakal BV, Cotton CAR, Bubeck D, Murray JW. Structural basis of light-induced redox regulation in the Calvin cycle. Proc Natl Acad Sci. 2019;116:20984-90.

7. Yu A, Xie Y, Pan X, Zhang H, Cao P, Su X, et al. Photosynthetic phosphoribulokinase structures: enzymatic mechanisms and the redox regulation of the Calvin-Benson-Bassham cycle. Plant Cell. 2020;32:1556-73.

8. Graciet E, Gans P, Wedel N, Lebreton S, Camadro J-M, Gontero B. The small protein CP12: a protein linker for supramolecular complex assembly. Biochemistry. 2003;42:8163-70. 
9. Marri L, Trost P, Trivelli X, Gonnelli L, Pupillo P, Sparla F. Spontaneous assembly of photosynthetic supramolecular complexes as mediated by the intrinsically unstructured protein CP12. J Biol Chem. 2008;283:1831-8.

10. Launay H, Barré P, Puppo C, Manneville S, Gontero B, Receveur-Bréchot $V$. Absence of residual structure in the intrinsically disordered regulatory protein CP12 in its reduced state. Biochem Biophys Res Commun. 2016;477:20-6.

11. Launay H, Barré P, Puppo C, Zhang Y, Maneville S, Gontero B, et al. Cryptic disorder out of disorder: encounter between conditionally disordered CP12 and glyceraldehyde-3-phosphate dehydrogenase. J Mol Biol. 2018;430:1218-34.

12. Fermani S, Trivelli X, Sparla F, Thumiger A, Calvaresi M, Marri L, et al. Conformational selection and folding-upon-binding of intrinsically disordered protein CP12 regulate photosynthetic enzymes assembly. J Biol Chem. 2012;287:21372-83.

13. Gontero B, Maberly SC. An intrinsically disordered protein, CP12: jack of all trades and master of the Calvin cycle. Biochem Soc Trans. 2012;40:995-9.

14. Erales J, Gontero B, Whitelegge J, Halgand F. Mapping of a copperbinding site on the small CP12 chloroplastic protein of Chlamydomonas reinhardtii using top-down mass spectrometry and site-directed mutagenesis. Biochem J. 2009;419:75-82.

15. Delobel A, Graciet E, Andreescu S, Gontero B, Halgand F, Laprévote $\mathrm{O}$. Mass spectrometric analysis of the interactions between $\mathrm{CP} 12$, a chloroplast protein, and metal ions: a possible regulatory role within a PRK/GAPDH/CP12 complex. Rapid Commun Mass Spectrom. 2005;19:3379-88.

16. Erales J, Lignon S, Gontero B. CP12 from Chlamydomonas reinhardtii, a permanent specific "chaperone-like" protein of glyceraldehyde-3-phosphate dehydrogenase. J Biol Chem. 2009;284:12735-44.

17. Li K, Qiu H, Zhou M, Lin Y, Guo Z, Lu S. Chloroplast protein 12 expression alters growth and chilling tolerance in tropical forage Stylosanthes guianensis (Aublet) Sw. Front Plant Sci. 2018;9:1319.

18. Howard TP, Fryer MJ, Singh P, Metodiev M, Lytovchenko A, Obata T, et al. Antisense suppression of the small chloroplast protein CP12 in tobacco alters carbon partitioning and severely restricts growth. Plant Physiol. 2011;157:620-31.

19. Elena López-Calcagno P, Omar Abuzaid A, Lawson T, Anne RC. Arabidopsis CP12 mutants have reduced levels of phosphoribulokinase and impaired function of the Calvin-Benson cycle. J Exp Bot. 2017;68:2285-98.

20. Singh $P$, Kaloudas $D$, Raines $C A$. Expression analysis of the Arabidopsis CP12 gene family suggests novel roles for these proteins in roots and floral tissues. J Exp Bot. 2008:59:3975-85.

21. Howard TP, Upton GJG, Lloyd JC, Raines CA. Antisense suppression of the small chloroplast protein CP12 in tobacco: a transcriptional viewpoint Plant Signal Behav. 2011;6:2026-30.

22. Launay H, Huang W, Maberly SC, Gontero B. Regulation of carbon metabolism by environmental conditions: a perspective from diatoms and other chromalveolates. Front Plant Sci. 2020;11:1033.

23. Mekhalfi M, Puppo C, Avilan L, Lebrun R, Mansuelle P, Maberly SC, et al. Glyceraldehyde-3-phosphate dehydrogenase is regulated by ferredoxinNADP reductase in the diatom Asterionella formosa. New Phytol. 2014;203:414-23.

24. Michels AK, Wedel N, Kroth PG. Diatom plastids possess a phosphoribulokinase with an altered regulation and no oxidative pentose phosphate pathway. Plant Physiol. 2005:137:911-20

25. Thieulin-Pardo G, Remy T, Lignon S, Lebrun R, Gontero B. Phosphoribulokinase from Chlamydomonas reinhardtii: a Benson-Calvin cycle enzyme enslaved to its cysteine residues. Mol Biosyst. 2015;11:1134-45.

26. Wilhelm C, Büchel C, Fisahn J, Goss R, Jakob T, LaRoche J, et al. The regulation of carbon and nutrient assimilation in diatoms is significantly different from green algae. Protist. 2006;157:91-124.

27. Erales J, Gontero B, Maberly SC. Specifity and function of glyceraldehyde3-phosphate dehydrogenase in a freshwater diatom, Asterionella formosa (bacillariophyceae). J Phycol. 2008;44:1455-64.

28. Clement R, Lignon S, Mansuelle P, Jensen E, Pophillat M, Lebrun R, et al. Responses of the marine diatom Thalassiosira pseudonana to changes in $\mathrm{CO}_{2}$ concentration: a proteomic approach. Sci Rep. 2017;7:42333.

29. Chen XH, Li YY, Zhang H, Liu JL, Xie ZX, Lin L, et al. Quantitative proteomics reveals common and specific responses of a marine diatom Thalassiosira pseudonana to different macronutrient deficiencies. Front Microbiol. 2018:9:2761.
30. Gschloessl B, Guermeur Y, Cock JM. HECTAR: A method to predict subcellular targeting in heterokonts. BMC Bioinform. 2008;9:393.

31. Emanuelsson $\mathrm{O}$, Nielsen $\mathrm{H}$, Heijne GV. ChloroP, a neural network-based method for predicting chloroplast transit peptides and their cleavage sites. Protein Sci. 1999;8:978-84.

32. Almagro Armenteros JJ, Tsirigos KD, Sønderby CK, Petersen TN, Winther O, Brunak S, et al. SignalP 5.0 improves signal peptide predictions using deep neural networks. Nat Biotechnol. 2019;37:420-3.

33. Armenteros JJA, Salvatore M, Emanuelsson O, Winther O, von Heijne G, Elofsson $\mathrm{A}$, et al. Detecting sequence signals in targeting peptides using deep learning. Life Sci Alliance. 2019;2:e201900429.

34. Xue B, Dunbrack RL, Williams RW, Dunker AK, Uversky VN. PONDR-FIT: a meta-predictor of intrinsically disordered amino acids. Biochim Biophys Acta. 2010;1804:996-1010.

35. Linding R, Jensen LJ, Diella F, Bork P, Gibson TJ, Russell RB. Protein disorder prediction: implications for structural proteomics. Struct Lond Engl. 2003;11:1453-9.

36. Mészáros B, Erdos G, Dosztányi Z. IUPred2A: context-dependent prediction of protein disorder as a function of redox state and protein binding. Nucleic Acids Res. 2018:46:W329-37.

37. Sormanni P, Camilloni C, Fariselli P, Vendruscolo M. The s2D method: simultaneous sequence-based prediction of the statistical populations of ordered and disordered regions in proteins. J Mol Biol. 2015:427:982-96.

38. McDonnell AV, Jiang T, Keating AE, Berger B. Paircoil2: improved prediction of coiled coils from sequence. Bioinformatics. 2006;22:356-8.

39. Vacic V, Uversky VN, Dunker AK, Lonardi S. Composition profiler: a tool for discovery and visualization of amino acid composition differences. BMC Bioinform. 2007:8:211.

40. Whitmore L, Wallace BA. Protein secondary structure analyses from circular dichroism spectroscopy: methods and reference databases. Biopolymers. 2008:89:392-400.

41. Sreerama N, Woody RW. Estimation of protein secondary structure from circular dichroism spectra: comparison of CONTIN, SELCON, and CDSSTR methods with an expanded reference set. Anal Biochem. 2000;287:252-60.

42. Micsonai A, Wien F, Bulyáki É, Kun J, Moussong É, Lee Y-H, et al. BeStSel: a web server for accurate protein secondary structure prediction and fold recognition from the circular dichroism spectra. Nucleic Acids Res. 2018:46:W315-22.

43. Mori S, Abeygunawardana C, Johnson MO, van Zijl PC. Improved sensitivity of HSQC spectra of exchanging protons at short interscan delays using a new fast HSQC (FHSQC) detection scheme that avoids water saturation. J Magn Reson B. 1995;108:94-8.

44. Stejskal EO, Tanner JE. Spin diffusion measurements: spin echoes in the presence of a time-dependent field gradient. J Chem Phys. 1965;42:288.

45. Delaglio F, Grzesiek S, Vuister GW, Zhu G, Pfeifer J, Bax A. NMRPipe: a multidimensional spectral processing system based on UNIX pipes. J Biomol NMR. 1995;6:277-93.

46. Lee W, Tonelli M, Markley JL. NMRFAM-SPARKY: enhanced software for biomolecular NMR spectroscopy. Bioinformatics. 2015;31:1325-7.

47. Eaton J, Bateman D, Haubert S, Wehbring R. GNU Octave version 4.2.1 manual: a high-level interactive language for numerical computations. 2017. https://www.gnu.org/software/octave/doc/v4.2.1/.

48. David G, Pérez J. Combined sampler robot and high-performance liquid chromatography: a fully automated system for biological small-angle $X$-ray scattering experiments at the Synchrotron SOLEIL SWING beamline. J Appl Crystallogr. 2009;42:892-900.

49. Petoukhov MV, Franke D, Shkumatov AV, Tria G, Kikhney AG, Gajda M, et al. New developments in the ATSAS program package for small-angle scattering data analysis. J Appl Crystallogr. 2012;45:342-50.

50. Receveur-Brechot V, Durand D. How random are intrinsically disordered proteins? A small angle scattering perspective. Curr Protein Pept Sci. 2012;13:55-75

51. Waterhouse A, Bertoni M, Bienert S, Studer G, Tauriello G, Gumienny $R$, et al. SWISS-MODEL: homology modelling of protein structures and complexes. Nucleic Acids Res. 2018;46:W296-303.

52. Launay H, Receveur-Bréchot V, Carrière F, Gontero B. Orchestration of algal metabolism by protein disorder. Arch Biochem Biophys. 2019;672:108070 
53. Nygaard M, Kragelund BB, Papaleo E, Lindorff-Larsen K. An efficient method for estimating the hydrodynamic radius of disordered protein conformations. Biophys J. 2017;113:550-7.

54. Dunker AK, Babu MM, Barbar E, Blackledge M, Bondos SE, Dosztányi Z, et al. What's in a name? Why these proteins are intrinsically disordered. Intrinsically Disord Proteins. 2013;1:e24157.

55. Zhang $Y$, Launay $H$, Schramm A, Lebrun $R$, Gontero B. Exploring intrinsically disordered proteins in Chlamydomonas reinhardtii. Sci Rep. 2018:8:6805.

56. Yruela I, Contreras-Moreira B. Protein disorder in plants: a view from the chloroplast. BMC Plant Biol. 2012;12:165.

57. Yruela I, Contreras-Moreira B, Dunker AK, Niklas KJ. Evolution of protein ductility in duplicated genes of plants. Front Plant Sci. 2018;9:1216.

58. Ward JJ, Sodhi JS, McGuffin LJ, Buxton BF, Jones DT. Prediction and functional analysis of native disorder in proteins from the three kingdoms of life. J Mol Biol. 2004;337:635-45.

59. Schad E, Tompa P, Hegyi H. The relationship between proteome size, structural disorder and organism complexity. Genome Biol. 2011;12:R120.

60. Kastano K, Erdős G, Mier P, Alanis-Lobato G, Promponas VJ, Dosztányi Z, et al. Evolutionary study of disorder in protein sequences. Biomolecules. 2020;10:1413.

61. Brodsky S, Jana T, Mittelman K, Chapal M, Kumar DK, Carmi M, et al. Intrinsically disordered regions direct transcription factor in vivo binding specificity. Mol Cell. 2020;79(459-471):e4.

62. Fuxreiter M, Tompa P. Fuzzy complexes: a more stochastic view of protein function. Adv Exp Med Biol. 2012;725:1-14.

63. Boeynaems S, Alberti S, Fawzi NL, Mittag T, Polymenidou M, Rousseau F, et al. Protein phase separation: a new phase in cell biology. Trends Cell Biol. 2018;28:420-35.

64. Jakob U, Kriwacki R, Uversky VN. Conditionally and transiently disordered proteins: awakening cryptic disorder to regulate protein function. Chem Rev. 2014;114:6779-805.

65. Hegyi H, Buday L, Tompa P. Intrinsic structural disorder confers cellular viability on oncogenic fusion proteins. PLoS Comput Biol. 2009;5:e1000552.

66. Marri L, Sparla F, Pupillo P, Trost P. Co-ordinated gene expression of photosynthetic glyceraldehyde-3-phosphate dehydrogenase, phosphoribulokinase, and CP12 in Arabidopsis thaliana. J Exp Bot. 2005;56:73-80.
67. Lebreton S, Graciet E, Gontero B. Modulation, via protein-protein interactions, of glyceraldehyde-3-phosphate dehydrogenase activity through redox phosphoribulokinase regulation. J Biol Chem. 2003;278:12078-84.

68. Oesterhelt C, Klocke S, Holtgrefe S, Linke V, Weber APM, Scheibe R. Redox regulation of chloroplast enzymes in Galdieria sulphuraria in view of eukaryotic evolution. Plant Cell Physiol. 2007;48:1359-73.

69. Matsumura H, Kai A, Maeda T, Tamoi M, Satoh A, Tamura H, et al. Structure basis for the regulation of glyceraldehyde-3-phosphate dehydrogenase activity via the intrinsically disordered protein CP12. Struct Lond Engl. 2011;19:1846-54

70. Boggetto N, Gontero B, Maberly SC. Regulation of phosphoribulokinase and glyceraldehyde 3-phosphate dehydrogenase in a freshwater diatom, Asterionella formosa. J Phycol. 2007;43:1227-35.

71. Lupas A. Coiled coils: new structures and new functions. Trends Biochem Sci. 1996;21:375-82

72. Burkhard P, Stetefeld J, Strelkov SV. Coiled coils: a highly versatile protein folding motif. Trends Cell Biol. 2001;11:82-8.

73. Parry DAD. Fifty years of fibrous protein research: a personal retrospective. J Struct Biol. 2014;186:320-34.

74. Rackham OJL, Madera M, Armstrong CT, Vincent TL, Woolfson DN, Gough J. The evolution and structure prediction of coiled coils across all genomes. J Mol Biol. 2010;403:480-93.

75. Newman JR, Wolf E, Kim PS. A computationally directed screen identifying interacting coiled coils from Saccharomyces cerevisiae. Proc Natl Acad Sci USA. 2000;97:13203-8.

76. Liu J, Rost B. Comparing function and structure between entire proteomes. Protein Sci Publ Protein Soc. 2001;10:1970-9.

77. Jensen E, Clément R, Maberly SC, Gontero B. Regulation of the CalvinBenson-Bassham cycle in the enigmatic diatoms: biochemical and evolutionary variations on an original theme. Philos Trans R Soc Lond B Biol Sci. 2017:372:20160401.

\section{Publisher's Note}

Springer Nature remains neutral with regard to jurisdictional claims in published maps and institutional affiliations.
Ready to submit your research? Choose BMC and benefit from:

- fast, convenient online submission

- thorough peer review by experienced researchers in your field

- rapid publication on acceptance

- support for research data, including large and complex data types

- gold Open Access which fosters wider collaboration and increased citations

- maximum visibility for your research: over 100M website views per year

At BMC, research is always in progress.

Learn more biomedcentral.com/submissions 